\title{
PRESERVAÇÃO E INTERVENÇÃO ARQUITETÔNICA NO ATUAL EDIFÍCIO DA MECÂNICA GERBASI: MUSEU MEMORIAL DA ANTIGA INDÚSTRIA BEBIDAS FUNADA
}

\author{
Dayane Tieme Yamada Carrenho, Lucas Augusto Blaia da Silva, Fabrícia Dias Da Cunha De Moraes \\ Fernandes Borges
}

Universidade do Oeste Paulista - UNOESTE, Faculdade de Engenharias e Arquitetura e Urbanismo, Presidente Prudente, SP. E-mail: dayaneyamada@yahoo.com.br, lucas blaia@hotmail.com, fabricia.arquiteta@gmail.com.

\section{RESUMO}

O presente artigo frisa a importância da discussão do processo de restauração e preservação do edifício considerado como um bem memoriável, e importante para a sociedade, apresentando uma proposta projetual de revitalização no atual edifício da Mecânica Gerbasi, localizada no município de Presidente Prudente/SP, que em sua composição abriga elementos arquitetônicos importantes que representam o contexto no qual foi construída, na década de 1940 e é expectadora das transformações e crescimento da cidade. Deste modo, este artigo trata do patrimônio industrial como bem cultural e social, baseado em teorias de proteção deste, alinhando tal edificação representativa para cidade, com a história da Indústria de Bebidas Funada, fundada em Presidente Prudente, também na década de 1940 e que representa uma parcela não só para os costumes locais dos cidadãos prudentinos, como também é atrelada a memória afetiva e simbólica para a cidade.

Palavras-chave: Patrimônio Industrial, Presidente Prudente, Bebidas Funada, Cartas Patrimoniais, Restauração.

\section{PRESERVATION AND ARCHITECTURAL INTERVENTION IN THE CURRENT GERBASI MECHANIC BUILDING: MEMORIAL MUSEUM OF THE OLD INDUSTRY FUNADA BEVERAGES}

\begin{abstract}
This article stresses the importance of the discussion of the process of restoration and preservation of the building considered a memorable and important building for society, presenting an architectural design proposal for revitalization in the existent one called Gerbasi Mechanics, in the municipality of Presidente Prudente / SP, which in its composition has important architectural elements representing the context in which it was built, in the 1940s and it's part of the transformation and growth of the city. Thus, this article deals with the industrial heritage as a cultural and social good, based on protection theoriess, aligning such a representative building for the city with the history of the industry Bebidas Funada, founded in Presidente Prudente, also in the 1940s and is a portion not only for the local citizens, it is also linked to affective and symbolic memory of the city.
\end{abstract}

Keywords: Industrial Heritage, Presidente Prudente, Bebidas Funada, Patrimonial Cards, Restoration. 


\section{INTRODUÇÃO}

Localizada no extremo oeste do Estado de São Paulo, Presidente Prudente é mais uma cidade que se desenvolveu economicamente através da exploração de produtos, que como afirma Santos (1999) era comum em cidades do interior Oeste Paulista ou Alto Sorocabana. Em 1930, foi inserida a linha férrea na cidade para atender a demanda de importação e exportação de matéria prima ao produto acabado, ligando assim a cidade a outros centros urbanos, onde Honda (2011) comenta que deste modo iniciou-se a instalação e concentração de residências, e de grandes indústrias e empresas ao longo desta, incluindo então, a antiga Tornearia Gerbasi, atual Mecânica Gerbasi.

Construída na década de 1940, a Tornearia Gerbasi, foi uma das edificações percussoras no desenvolvimento espacial e industrial da cidade, além de ser um marco para a paisagem urbana, por ser um edifício detentor de características singulares no meio do atual centro da cidade, onde evidencia sua identidade patrimonial industrial da época, através de seus tijolinhos de barro aparente, o que torna fundamental a discussão do seu restauro e preservação.

A preservação do edifício histórico industrial está ligado ao desenvolvimento significativo cultural de uma cidade, algo memorável para qualquer indivíduo. Beatriz Kuhl (2008), uma das maiores estudiosas sobre tal tema, enfatiza sobre o grande valor da conservação da identidade e restauro de sítios industriais.

Com intuito de evidenciar a aplicação dos atuais conceitos teóricos, destacando as cartas patrimoniais que possam direcionar resultados positivos através de grandes conceitos de restaurações, como por exemplo, a "brandiana", desenvolvida por Cesare Brandi (2004), e a Carta de Veneza (1964) norteadores do processo de preservação (BRANDI, 2004).

Assim, o objetivo geral desta proposta projetual, é evidenciar e identificar as necessidades relativas físicas e teóricas da pré-existência histórica da antiga Tornearia Gerbasi, acoplado com o resgate de sua memória, alinhando a preservação da história da Bebidas Funada, fundada e localizada na cidade Presidente Prudente-SP, local que possui relevâncias histórico-sociais, que nos quais precisa ser exaltado e evocado para e pela população.

Visando manter as mesmas características industriais do conjunto da atual Gerbasi, respeitando o caráter material e estético, a fim de propor um projeto de reconfiguração do espaço, através de um Museu dedicado à Bebidas Funada, no qual possa se correlacionar com a dinâmica urbana, através de anexos contemporâneos à pré-existência, propiciando assim a oferta de espaços históricos para sociedade, ressaltando a melhoria do ambiente urbano, qualidade da transmissão de seus valores culturais, pedagógicos, históricos e materiais e imateriais para gerações futuras.

\section{METODOLOGIA}

A metodologia adotada é baseada em levantamento bibliográfico, pesquisa documental, adjunto a leituras físicas in loco, na área da preexistência abordada.

O levantamento bibliográfico, permitiu refletir, identificar e nortear sobre as questões relativas a arquitetura patrimonial, preservação e memória pertinentes a este trabalho. Com as leituras realizadas desde o entorno da preexistência, à própria edificação arquitetônica permitiuse elaborar a proposta de maneira que evoque tal espaço e valorize tal edificação e assim a paisagem onde está inserida.

\section{MECÂNICA GERBASI.}

A preexistência é o ponto de partida do projeto, a mesma é um edifício da década de 1940, período este que simboliza um momento de suma importância para a história de Presidente Prudente, na qual a cidade passava por grandes mudanças socioeconômicas, e que é relacionada 
diretamente com a estação ferroviária, símbolo das atividades e crescimento da cidade. (RESENDE, 2006).

A edificação se encontra há poucos metros da antiga estação ferroviária, na qual ficava com seu acesso principal em frente as portas da estação, por assim dizer. Com isso, muitas obras que se localizavam nesse mesmo eixo da av.: Brasil no qual a preexistência se encontra, resultaram em localizações estratégicas e privilegiadas em relação a malha urbana da cidade.
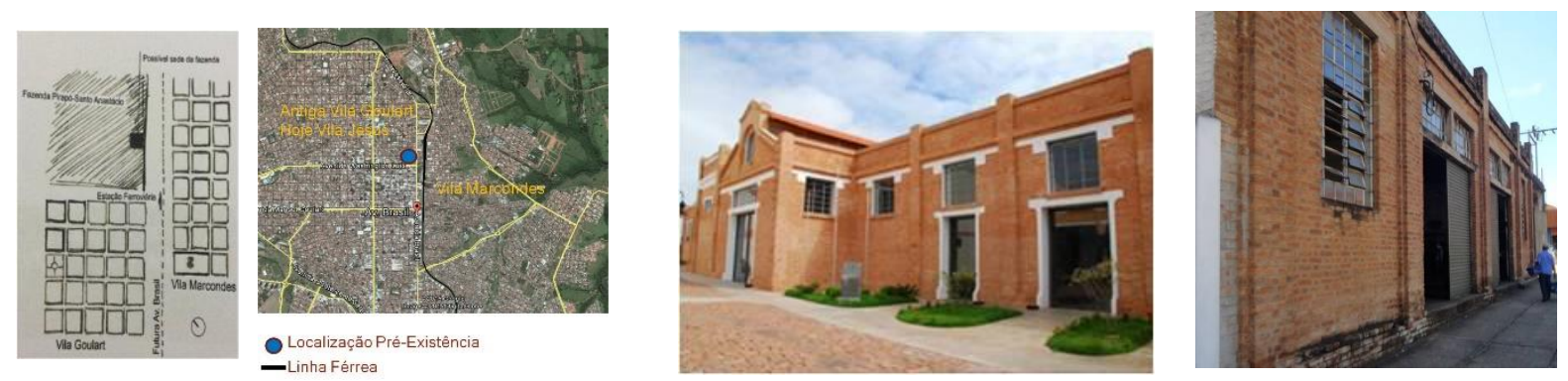

Figura 01. a) Mapa esquemático do inicio da urbanização na cidade; b) Localização atual c) Centro Cultural Matarazzo, d) Atual fachada Mecânica Gerbasi.

Fonte: A)HONDA, 2001; B) Localização: Maps (2015), esquematizada pelos autores; C) Autores (2015), D Autores (2015)

A obra implantada carrega em si toda a história que ela viu como expectadora diante de todo seu entorno e ao mesmo tempo, personagem ativo ao longo de todos esses anos. $\mathrm{O}$ estilo da preexistência reflete a época em que foi implantado, estilo este que era comumente encontrado nesse período, o industrial. Na região da preexistência e é claro, da estação ferroviária é comum encontrarmos obras que seguem a mesma composição estilística, grandes barracões em alvenaria estrutural e seus tijolos maciços, treliças de madeira e telhas de barro, um exemplo disso é o atual centro cultural Matarazzo (Figura 1-c) (RESENDE, 2006).

\section{PROPOSTA - MUSEU.}

Os museus têm se tornado cada vez mais populares, divertidos, comunicativos e interativos ao longo dos anos, e vêm se tornando por muitas vezes atrações chaves para as cidades onde estão localizados, servindo como uma referência não só turística, como também dentre a paisagem urbana inserida. (MONTANER, 2003, p. 94)

Com base nisso, a proposta se delineia em um Museu que possa obter um diferencial, no desejo em que ele deixe de ser algo apenas para contemplação ao público, onde o público se torne próprio agente de interação do mesmo. Algo que tem se visto cada vez mais em museus contemporâneos.

Atualmente, há uma constante tendência em se preocupar em preservar a memória, assim como não só cabe apenas aos historiadores, arqueólogos, arquitetos e urbanistas, a missão de preservar o passado, a memória também não fica apenas restrita aos antropólogos, cientistas sociais e etnólogos. Qualquer indivíduo pode ser historiador de si mesmo e do grupo à qual pertence referente ao patrimônio, seja da arquitetura, ao material e imaterial, a questão vem se tornando cada vez mais intensa dentre a sociedade (CUNHA, 2004).

\section{TEMA - BEBIDAS FUNADA.}

O tema escolhido para a proposta do museu em Presidente Prudente foi pensada para que remetesse e conectasse com a história, e que se harmonizasse com o contexto em que a preexistência está implantada e tivesse alguma relação com aquele momento em que o edifício foi construído. 
Com isso veio a inspiração de algo tipicamente Prudentino, que nasceu aqui nesta cidade e que cresceu junto a ela, a história da Bebidas Funada, e em especial a tubaína Funada! Não há um só prudentino que não conheça ou que tenha tomado a antiga bebida, logo, em que ela estivesse presente ao longo da sua vida, e participado de sua infância.

Para muitos prudentinos, o refrigerante tem "gosto de infância", onde muitos se lembram de tomar nos pátios da escola, na hora do intervalo, bebendo pela garrafa pequena, conhecida como "caçulinha" ou no saquinho de plástico e canudo...dividindo com os colegas, sob a sombra de uma arvore...ah, quantas memórias! Ou ainda então, é comum encontrar prudentinos na feiralivre seja do bairro, seja a principal na Av.: Manoel Goulart (uma das principais vias da cidade) dentre as barraquinhas ou trailers para comer um pastel juntamente com a típica bebida, ou então na cantina dos clubes dos mais tradicionais aos mais populares da cidade.

Indo mais além, é comum as pessoas naturais da cidade e que moram fora da mesma, e que são fãs da marca, terem o costume de toda vez que vêm visitar a sua cidade natal de tomar a bebida, e até levar da mesma junto consigo nas viagens. Esses costumes, podem se relacionar as vivências, e consequentemente a memória, isso é identidade, isso é cultura. No qual tira o cidadão do lugar comum da esfera cada vez mais globalizada e os remete a um espaço tipicamente seu, elevando a um valor intransferível e sem igual.

A arquitetura pode remeter a tudo isso, a rememorar o passado, e permitir sentir e viver a aquilo que ela traduz em si.

\section{HISTÓRIA BEBIDAS FUNADA.}

A Bebidas Funada nasceu e cresceu em Presidente Prudente, o que é interessante é que tanto o nascimento da Bebidas Funada quanto da Mecânica Gerbasi (preexistência) foram na mesma época, ambas na década de 1940 o que ajuda inter-relacionar as duas histórias.

Figura entre as maiores empresas de Presidente Prudente, a Bebidas Funada é símbolo de desenvolvimento industrial para a cidade. Os traços dessa história, feita de trabalho e perseverança, começaram a ser traçados em 1932, quando o patriarca Mampei Funada (Figura 02) chegou ao Brasil com sua esposa e filhos. Começando a tomar forma em 1947, com a instalação da fábrica de bebidas "Funada e Filhos", que contava com o trabalho do senhor Mampei, de seus filhos e um carroceiro que fazia o transporte das bebidas. (FUNADA, 200-?).

De acordo com Funada (200-?) A capacidade de produção da fábrica nessa época era de 150 garrafas por hora, entre guaraná, soda limonada, água tônica, vinagre entre outros. Com muito esforço e pouca tecnologia, afinal estavam em 1947, a família Funada investiu no empreendimento. Em 1952, a fábrica passou a se chamar "Indústria e Comércio de Bebidas Funada Ltda". E se especializou na produção de refrigerantes (guaraná, soda limonada, laranjada "Mican" e a tão tradicional tubaína.

Figura 02. Imagens que compõe a história da bebida.
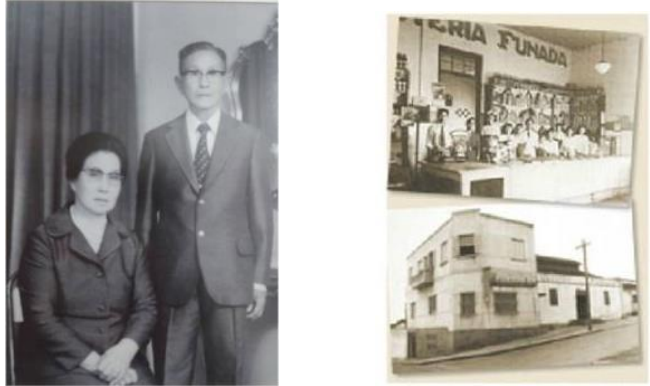

Fonte: a) Sr. Mampei e sua esposa - Acervo pessoal, Henrique Funada (2015); b) Antiga fábrica de bebidas - em: http://www.funada.com.br/hotsite/linha_do_tempo/index.html, acesso em 08 de agosto de 2016.

Desde então, a Funada não parou mais de crescer, investindo cada vez mais em tecnologia até chegar ao que é hoje, uma potência no segmento de refrigerantes. Atualmente a Bebidas conta com turnos ininterruptos de produção e equipamentos modernos de última geração. Tudo 
isso para atender a grande demanda de seus refrigerantes, que são vendidos em diversos estados brasileiros, além de exportações para o Paraguai, Bolívia e Japão. (FUNADA, 200-?)

A Bebidas Funada também nasceu no mesmo cenário da Mecânica Gerbasi, e ambas compartilham a história de Presidente Prudente entre si e fazem parte de um importante momento para a cidade, e consequentemente para a região...relacionando e valorizando nossas raízes, nada melhor que unir a arquitetura icônica da Mecânica Gerbasi a este símbolo Prudentino, a Tubaína Funada.

\section{O PROJETO.}

Com base em tudo que foi exposto até então, sobre a relação da Tubaína Funada com a identidade e história do prudentino, suas memórias e suas vivências, o desejo projetual era em apresentar uma proposta que transmitisse uma forma harmônica, natural e sensorial. A fim de evocar os sentimentos do público, transformando o local em uma capsula de agradáveis sensações.

Com base nas leituras realizadas in loco, desde o entorno que abrange a preexistência, e a própria edificação, foi-se concluído que o aspecto resultante da área estudada, é de uma paisagem monótona, sem atrativos que façam o público transeunte parar, olhar e participar daquele espaço de maneira vívida e instigante. Não há espaços verdes e áreas abertas de contemplação e convivência próxima a preexistência.

Com isso, foi elaborada uma forma que respondesse as estas atuais carências levantadas nas leituras, juntamente ao que possa representar o tema da proposta de maneira que ao mesmo tempo respeite, enalteça a edificação preexistente. $A$ forma desenhada remete à fluidez e leveza da bebida, onde se abre a céu aberto, e que referência aos primórdios tempos de colégio, aos pátios de escola onde muitos prudentinos tinham o contato com a bebida. Tal forma tem o intuito de provocar sensações e rememorar o usuário.

O projeto foi pensado para aproveitar, preservar e valorizar o edifício preexistente como um todo. Os barracões principais seriam mantidos e serviriam como salas expositivas que contassem a história da família Funada alinhada a história da fábrica junto a história de Presidente Prudente, com divisórias em drywall para que não interferisse na estrutura já existente. Foi projetado um corredor de ligação que se conectasse com o último barracão onde seria uma sala de projeção.

Figura 03. Proposta projetual: Planta Baixa e Maquete volumétrica.
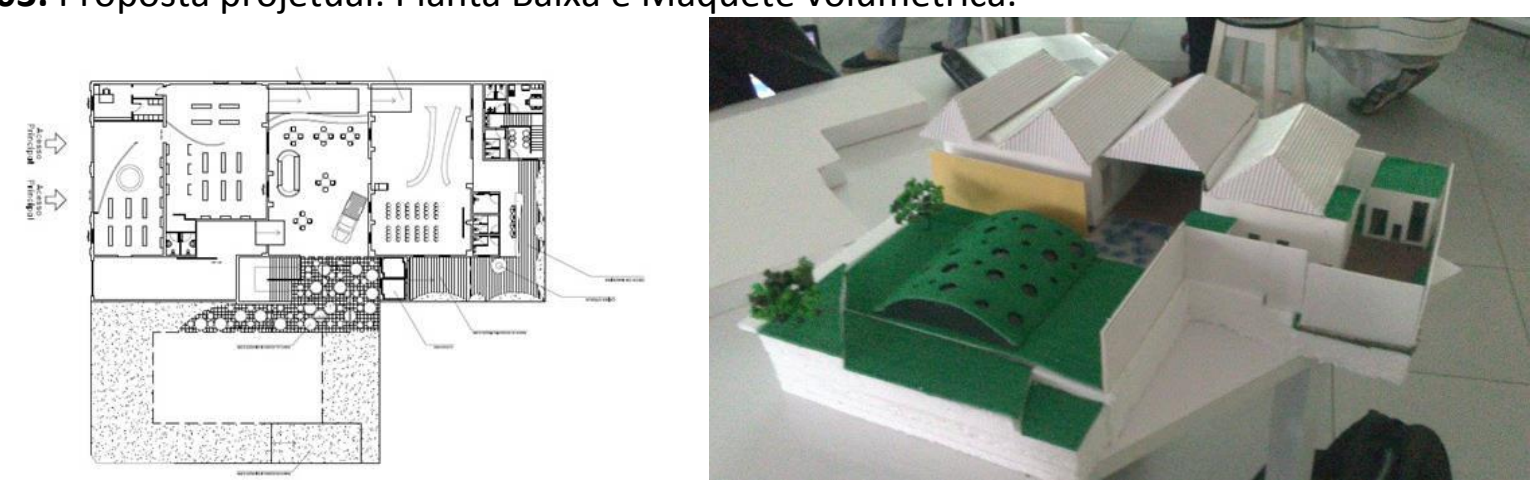

Fonte: Autores, 2016.

Sendo esse um espaço aberto ao público, que dá acesso à via pública, o público mesmo que não tenha entrado ao museu, teria acesso a esse espaço, podendo desfrutar do produto, adquirir produtos e ainda apreciar o prédio da pré-existência. Tornando o espaço de convivências um lugar de íntima integração entre as relações do público e privado, interno e externo.

Esse espaço aberto se conecta com o grande destaque do projeto, o "Espaço bolha", projetado onde atualmente se encontra o estacionamento da preexistência e parte de uma propriedade vizinha, o espaço é composto por uma praça com bancos e árvores que abriga uma 
grande estrutura em forma de semicírculo enterrada ao chão, revestida em grama, assim como todo o espaço, evocando a fluidez presente e forma orgânica, adjetivos da tubaína Funada, já a estrutura ainda apresenta recortes circulares em diversas dimensões, remetendo as bolhinhas de gás do refrigerante.

Sob essa semiesfera, encontra-se um espaço interativo dedicado especialmente ao fã da bebida, com acesso através de elevador e escada. Onde permite explorar um espaço sensorial, emitido pelo jogo de luz e sombra provocado pela implantação abaixo do térreo, adicionado ao fechamento da cobertura com a iluminação causada pelo recorte das diferentes escalas circulares, "as bolhas".

No espaço externo foi proposto a implantação de bancos e árvores na intenção de se fazer um convite ao público (mesmo os que não entrem ao museu), a participar desse processo de troca. A desfrutar da bebida e rememorar o passado, a infância, tomando a tubaína no saquinho de plástico, debaixo de uma árvore sentado a um banco, que rememore aos tempos de escola aos recreios no pátio da escola.

O desejo é de transportar as pessoas física e emocionalmente com o projeto.

\section{CONCLUSÃO}

A intenção da proposta é valorizar e preservar tal edifício, cujo desejo é que a sociedade aprenda a olhá-lo, senti-lo e vivencia-lo por aquilo que vai além da das suas paredes e telhado, a sua significância!

Tendo consciência de toda a significância em que a preexistência representa, adjunto a história da Bebidas Funada, considera-se a obra de preexistência aqui abordada, como uma jóia... Uma jóia da cidade, da memória, da identidade do prudentino, e de sua cultura. Onde essa jóia precisa ser lapidada e valorizada ao olhar da sociedade.

Assim, a proposta teve como objetivo enaltecer a memória adjunto a importância do patrimônio, a fim de valorizar o espaço onde a preexistência está implantada, a edificação e sua relevância, de modo que seja explorada as potencialidades do local, sem que degradasse ou interviesse na estrutura, com uma intervenção harmoniosa, atrativa e condizente com o contexto histórico, arquitetônico e espacial.

\section{REFERÊNCIAS}

BRANDI, C; Tradução Kuhl, B. Teoria da restauração. 1. ed. Cotia, SP: Atelie Editorial, 2004.

CUNHA, Claudia dos Reis e. A atualidade do pensamento de Cesare Brandi.Resenhas Online, São Paulo, ano 03, n. 032.03, Vitruvius, 2004 <http://www.vitruvius.com.br/revistas/read/resenhasonline/03.032/3181>. Acesso em: 07 ago 2016.

FUNADA. Linha do tempo. 200-?. Disponível em: < http://www.funada.com.br/hotsite/linha_do_tempo/index.html>. Acesso em: 08 ago. 2016.

HONDA, S. C. A. L. Habitação de baixa renda como produto de capital: o programa de arrendamento residencial (PAR) em Presidente Prudente - SP. 2011.189 f. Tese (Doutorado) Universidade Presibiteriana Mackenzie, São Paulo - SP.

MONTANER, J. M. Museus para o século XXI. Barcelona: Gustavo Gili, 2003. P. 94.

RESENDE, B. T. Raízes prudentinas. 1. Ed. São Paulo: Presidente Prudente, 2006. 
SANTOS, W. Diagnóstico histórico e econômico da região de Presidente Prudente. Presidente Prudente: Waldery Santos/Jornalismo e pesquisa de história, 1999. 171 p. 